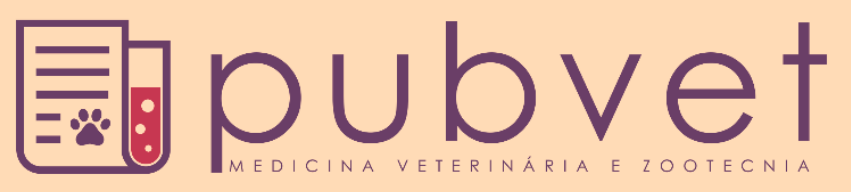

https://doi.org/10.31533/pubvet.v16n02a1031.1-17

\title{
Recuperação de pastagem degradadas com utilização de biossólido e Moringa oleifera: Revisão
}

\author{
Pamela Fernanda Carvalho Martins ${ }^{1}$, Rafaela Thais Benedito Alves ${ }^{2 *}$, Jessica Thais Gabe ${ }^{1 \bullet}$, \\ Danaila Bruneli Fernandes Gama ${ }^{3}{ }^{\circ}$, Rafael Oliveira Lima ${ }^{\circ} \mathbb{C}^{\circ}$, Paulinho Santos da Silva ${ }^{\circ}$,

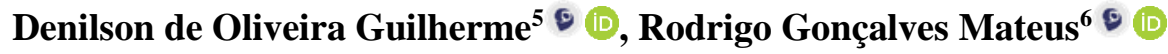 \\ ${ }^{1}$ Discente do Curso de Engenharia Agronomia, Universidade Católica Dom Bosco - UCDB, Campo Grande - MS - Brasil. \\ ${ }^{2}$ Doutorandado Programa de pós-graduação em Ciências Ambientaise Sustentabilidade Agropecuária, Universidade CatólicaDom Bosco-UCDB, Campo Grande-MS-Brasil. \\ ${ }^{3}$ Mestrando(a) do Programa de pós-graduação em Ciência Animal, Universidade Federal do Mato Grosso do Sul-UFMS, Campo Grande - MS - Brasil. \\ ${ }^{4}$ Engenheiro Agrônomo, Instituto São Vicente - Fazenda Lagoa da Cruz, Universidade Católica Dom Bosco-UCDB, Campo Grande - MS - Brasil. \\ ${ }^{5}$ Coordenadordo Programa de pós-graduação em Ciências Ambientaise Sustentabilidade Agropecuária, Universidade CatólicaDomBosco-UCDB, Campo Grande-MS-Brasil. \\ ${ }^{6}$ Docente do Programa de pós-graduação em Ciências Ambientais e Sustentabilidade Agropecuária, Universidade Católica Dom Bosco-UCDB, Campo Grande - MS-Brasil. \\ *Autor para correspondência, E-mail: rafahbenedito@gmail.com
}

Resumo. A pecuária ocupa lugar de destaque na economia brasileira, principalmente a bovinocultura de corte e leite, assim o sucesso desse setor é primordial para o crescimento do país. Porém, a produtividade deste setor está intimamente ligada a qualidade das pastagens, pois essas são a principal fonte alimentar dos bovinos, e cerca da metade das pastagens brasileira encontra-se com algum grau de degradação, diminuindo assim a produtividade e rentabilidade desse setor. Devido a isso, a busca por tecnologias de recuperação de pastagens vem sendo pesquisadas, sobretudo as que diminuam os custos no processo de recuperação, procurando aumentar a produtividade e qualidade das pastagens, preservar o meio ambiente e maximizar os lucros para os produtores. Visto isso, o uso de novas fontes de adubação e a implantação de sistemas silvipastoris tem sido amplamente estudado e aplicado para recuperação dessas áreas, dentre eles podemos destacar o uso de biossólido que um adubo orgânico proveniente do tratamento de esgoto sanitário, assim como a implantação de pecuária-floresta utilizando Moringa oleífera uma planta leguminosa a qual fixa nitrogênio no solo e pode servir como fonte alimentar para os animais. Sendo assim, nesse trabalho está descrito o cenário da degradação e pastagens brasileiras e o uso de biossólido e moringa na recuperação dessas áreas.

Palavras chave: Integração pecuária-floresta, lodo de esgoto, rhizobium

\section{Recovery of degraded pasture using biosolids and Moringa oleifera: Review}

Abstract. Livestock occupies a prominent place in the Brazilian economy, especially beef and dairy cattle raising, so the success of this sector is essential for the country's growth. However, the productivity of this sector is closely linked to the quality of pastures, as these are the main food source for cattle, and about half of the Brazilian pastures are with some degree of degradation, thus reducing the productivity and profitability of this sector. Because of this, the search for pasture recovery technologies has been sought, especially those that reduce costs in the recovery process, seeking to increase pasture productivity and quality, preserve the environment and maximize profits for producers. In view of this, the use of new sources of fertilization and the implementation of silvopastoral systems has been widely studied and applied to the recovery of these areas, among them we can highlight the use of biosolids, which is an organic fertilizer from the treatment of sanitary sewage, as well as the implementation of livestock-forest using Moringa oleifera a leguminous plant which fixes nitrogen in the soil and can serve as a food source for the 
animals. Thus, this work describes the scenario of degradation and Brazilian pastures and the use of biosolids and moringa in the recovery of these areas.

Keyword: Livestock-forest integration, sewage sludge, rhizobium

\section{Introdução}

As áreas com pastagens degradadas são um dos maiores gargalos da produtividade da bovinocultura brasileira, já que a maior parte do rebanho nacional é criado a pasto, o qual é utilizado como a principal fonte nutricional do rebanho (Ferraz \& Felício, 2010). Cerca de 100 milhões de hectares de pastagens estão degradadas no Brasil, acarretando menor produtividade de matéria verde, maior tempo de reestabelecimento pós pastoreio, entre outros fatores que potencializam as percas do setor (Muller et al., 2001; Peron \& Evangelista, 2004).

Várias tecnologias e fontes de matéria orgânica tem sido utilizada com o objetivo de recuperação de áreas degradadas, o biossólido é uma delas, revelando-se como uma alternativa viável. O uso agrícola do lodo de esgoto/biossólido como adubo orgânico é considerado como a alternativa mais promissora de disposição final desse resíduo, principalmente na recuperação de áreas de pastagens degradadas (Campos \& Alves, 2008). O biossólido tem-se revelado um importante insumo agrícola, de interesse na recomposição de solos degradados, bem como na fertilização das culturas, de preferência aquelas que não são de consumo direto pelos seres humanos. A aplicação desses materiais orgânicos em áreas degradadas traz benefícios nas propriedades físicas, químicas e biológicas dos solos (실 et al., 2005).

A integração pecuária-floresta é uma alternativa que também favorece a recuperação de áreas degradadas, principalmente com o consórcio de leguminosas arbóreas, pois fixam nitrogênio ao solo, potencializam a reciclagem dos nutrientes das camadas mais profundas para a superfície do solo (Silva et al., 2015a), assim o processo de recuperação natural do solo é potencializado (Pott et al., 2007). Sendo assim, o uso da Moringa oleifera $L$. no consórcio com pastagens degradadas traz benefícios, pois se trata de uma leguminosa forrageira, a qual também pode ser utilizada como alimento para os animais (Olson \& Fahey, 2011).

\section{Degradação pastagens}

A pecuária brasileira conta com o maior rebanho bovino do mundo, é o maior exportador de carne e o sexto maior produtor de leite, sendo assim um dos setores mais importantes do agronegócio e para a economia do país. Apesar de ser um setor de destaque a bovinocultura conta com uma baixa produtividade devido à falta de investimento em tecnológica e a baixa de lotação das pastagens (Muller et al., 2001; Peron \& Evangelista, 2004).

A criação de bovinos no Brasil em sua grande maioria utiliza sistemas extensivos, tendo como base alimentar o pasto (Ferraz \& Felício, 2010; Oliveira et al., 2013), sendo assim pastagens de alta produtividade e qualidade é essencial para o sucesso da atividade. A maior parte das pastagens brasileiras são formadas por espécies oriundas da África como os gêneros Urochloa, Panicum e Andropogon, esses gêneros são prediletos por serem resistentes ao período seco e pela baixa exigência de nutrientes no solo (Carvalho et al., 2017; Santini et al., 2015).

Em 2018. a área ocupada por pastagens no Brasil era de 180.890.097 hectares, correspondente a $21,3 \%$ do território brasileiro, deste total 94.851 .837 hectares são de pastagens degradada, sendo assim $56,2 \%$ das pastagens brasileiras encontram-se com baixo potencial produtivo. No Mato Grosso do Sul, a área total de pastagem é de 15.958.039 hectares, sendo que 57,2\% dessas pastagens apresentam algum grau de degradação (LAPIG, 2018). Nesse cenário um dos maiores impasses da pecuária brasileira é a degradação das pastagens, gerando uma menor rentabilidade para o setor (Macedo, 2005; Peron \& Evangelista, 2004). Na Figura 1 estão demonstrados o grau de degradação das pastagens brasileiras e Mato Grosso do Sul.

O processo de degradação das pastagens pode ser caracterizado pela diminuição do vigor, produtividade e qualidade das plantas, perca da capacidade de recuperação, suscetibilidade a pragas, doenças e plantas daninhas (Dias-Filho, 2003; Santini et al., 2015). Dentre as principais causas da degradação de pastagens podemos citar o manejo inadequado da forrageira, falta de conservação do solo 
e exaustão da sua fertilidade, assim como ausência da reposição de nutrientes e alterações climáticas

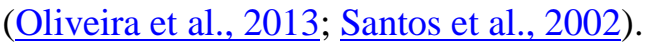

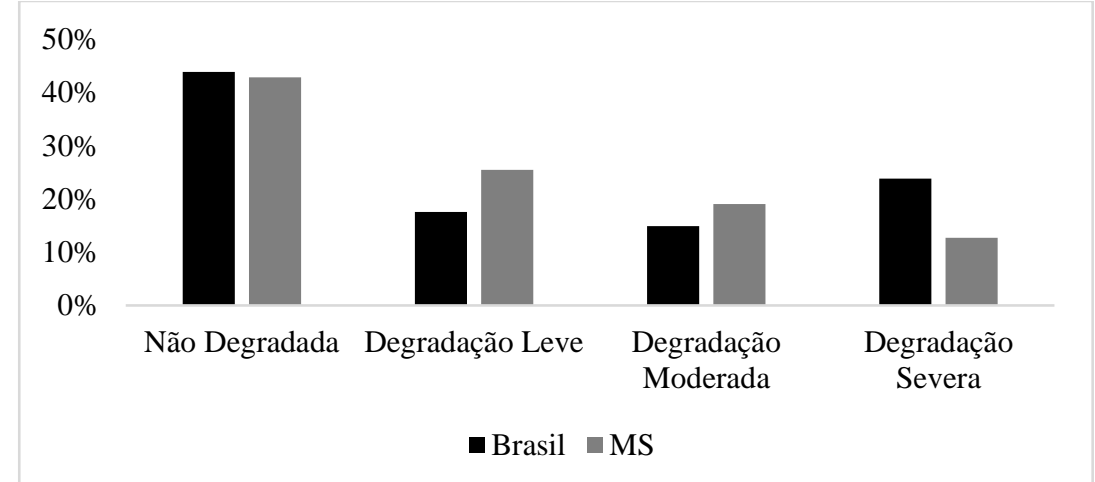

Figura 1. Grau de degradação das pastagens brasileiras e sul matogrossenses. Fonte: LAPIG, 2018.

\section{Recuperação de pastagens degradadas}

A recuperação de pastagens degradadas é de extrema importância ambiental, pois diminui a necessidade de expansão de áreas de pastagens, minimizando assim a destruição das áreas de preservação ambiental. Outro fator ambiental importante é que aumentando a produtividade há a diminuição da emissão de gases do efeito estufa por animal, sendo assim o setor se torna melhor do ponto de vista produtivo e ambiental (MCTI, 2014; Zen et al., 2008).

Para iniciar o processo de recuperação de pastagens é necessário um diagnóstico prévio da situação da área e uma análise para determinar qual a melhor forma de recuperação, dentre as mais utilizadas podemos destacar as formas direta e indireta. A recuperação direta é utilizada em pastagens com menor grau de degradação e consiste na utilização de métodos mecânicos e químicos (adubação e calagem). Já a indireta é recomendada áreas com degradação mais acentuada por meio do consórcio entre pastagem e outra cultura, assim como os sistemas silvipastoris (Aguirre et al., 2014; Naranjo et al., 2012; Ribeiro et al., 2007).

Visando a diminuição da emissão de gases do efeito estufa (GEE) no setor agropecuário, o governo criou o Plano Setorial de Agricultura de Baixa Emissão de Carbono (ABC), que tem como objetivo estimular o uso de forrageiras apropriadas, tornar as pastagens degradadas produtivas e evitar a degradação de novas áreas de pastagem. O plano conta com sete programas, dos quais seis são de mitigação, dentre eles os Sistemas Agroflorestais (SAF's) (BRASIL, 2012). Os sistemas agroflorestais associam a produção agrícola e o plantio de espécies arbóreas, as quais são utilizadas para reflorestamento e melhoramento da área degradada, sendo assim esses sistemas mantem a produtividade da área e a recupera pela interação entre os componentes e melhorias na qualidade do solo ((Ribaski et al., 2001; Santos et al., 2016).

O uso de fertilizantes para a recuperação das pastagens gera uma boa reposição de nutrientes ao solo, porém o investimento financeiro é muito alto, tornando-se muitas vezes inviável ao produtor, sendo assim sistemas que proporcionam recuperação da área com menor custo ou melhor custo benefício vem destacando-se como o uso dos SAF's, pois faz a recuperação da área e a mantém produzindo (Barcellos et al., 2008; Martins et al., 2009; Zen et al., 2008).

\section{Uso de leguminosas no sistema silvipastoril para a recuperação de pastagens}

Uma das estratégias utilizada em um projeto de recuperação de áreas de pastagens degradadas é o consórcio com leguminosas arbóreas que se mostra como boa alternativa para melhora dessas áreas, pois além de fixar nitrogênio, tem efeitos positivos na fertilidade como a reciclagem dos nutrientes das camadas mais profundas para a superfície do solo (Silva et al., 2015b). O uso de leguminosas na recuperação de áreas degradadas é uma técnica com aplicação em diversos ambientes e objetiva criar condições para acelerar o processo de recuperação natural do ecossistema (Costa, 1995; Olivo et al., 2009).

De acordo com Barcellos et al. (2008) o uso de leguminosas é uma prática recomendada para recuperação de áreas degradadas, pois as leguminosas arbóreas diminuem a força das enxurradas, protegendo o solo da erosão. Outro grande benefício do seu uso, é pela capacidade de fixação do 
nitrogênio atmosférico em simbiose com Rhizobium e a baixa razão carbono e nitrogênio, permitem a decomposição e liberação de nutrientes para a cultura em consócio (Ázcon-Aguilar \& Barea, 1978).

A implantação de sistema Integração Pecuária Floresta (IPF) traz algumas vantagens e vem-se mostrando como uma alternativa viável de produção para recuperação de áreas de pastagem degradadas, como também na reforma ou renovação dos pastos e aumento de produtividade, gerando benefícios econômicos, sociais ambientais. Alguns destes benefícios são a conservação e a melhoria da condição física e biológica do solo, a conservação dos recursos hídricos, a promoção do sequestro de carbono e o aumento na biodiversidade (Assis et al., 2019; Faria, 2014; Varella et al., 2009).

Estas características viabilizam o seu uso na elaboração dos Projetos de Recuperação de Áreas Degradadas (PRADs) e em programas de reflorestamento, silvicultura, sistema silvipastoris (Bernardino \& Garcia, 2009). O cultivo das árvores foi comprovado em programas de reflorestamento, proteção e fertilização do solo, pois traz muitos nutrientes ao solo, além de protegê-lo de fatores externos (erosão e perda de água), além disso tem fácil propagação (sexuada ou assexuada), pode ser cultivada em solos de baixa fertilidade e com escassez de chuva, já que essas plantas demonstram habilidade de sobreviver em condições adversas e em solos marginais, o que representa uma vantagem para o cultivo nos mais diversos ambientes (Cordeiro et al., 2015). Dentre esse cenário, algumas pesquisas vêm sendo desenvolvidas com o uso de leguminosas para a recuperação de pastagens e melhoria na qualidade do solo; porém, a grande maioria relata o uso de leguminosas anuais e pouco fala-se das leguminosas perenes. Dentre os estudos de ambas as leguminosas, podemos destacar os descritos abaixo.

Freitas et al. (2013) analisaram o aporte de serapilheira e de nutrientes no solo em dois tratamentos: T1: milho (Zea mays) + eucalipto (híbrido - Eucalyptus grandis x E. urophylla) + acácia (Acacia mangium) + braquiária (Brachiaria decumbens); e o sistema 2: milho + eucalipto + braquiária, o plantio tambem foi modificado em diferentes parcelas, sendo utilizados 1, 3 e 6 metros entre as plantas. Após 36 meses a serapilheira e a pastagens começaram a ser coletadas mensalmente durante 1 ano e submetidas a avaliação de produtividade e o teor de nutrientes: $\mathrm{N}, \mathrm{P}, \mathrm{K}, \mathrm{Ca}, \mathrm{Mg}$ e $\mathrm{S}$. Exceto o P, todos outros nutrientes tiveram maior deposição nos tratamentos em sistemas agrossilvipastoris, com destaque para os tratamentos com o plantio de acácia que promoveu maior deposição de $\mathrm{N}$ no solo, mostrando que a espécie leguminosa aumenta a produção de serapilheira e de nutrientes no solo, sendo mais eficiente na recuperação e manutenção de pastagens degradadas.

Diehl et al. (2014) avaliaram três diferentes sistemas agrossilvipastoris: capim elefante (CE) + azevém $(\mathrm{AZ})+$ espécie de crescimento espontâneo (ECE), CE + AZ + ECE + amendoim forrageiro $(\mathrm{AM})$ e a terceira $\mathrm{CE}+\mathrm{AZ}+\mathrm{ECE}+$ trevo vermelho (TV). Foram coletadas amostras de pastos simulando o pastejo para determinar os teores de proteína bruta (PB), fibra em detergente neutro (FDN), digestibilidade in situ da matéria seca (DISMS) e da matéria orgânica (DISMO). Sendo assim, o uso de leguminosas em ambos os sistemas acarreta no menor valor nutritivo da pastagem, pois demonstram maiores teores de PB e DISMO, e menor teor de FDN.

O estudo realizado por Pegoraro et al. (2014) mostra que o cultivo de de Acacia mangium e o aumento do tempo de cultivo do eucalipto proporcionam ao solo maior estoque de $\mathrm{C}$ e $\mathrm{N}$ nas frações lábeis e estáveis, os valores ficam próximos aos valores de mata nativa, mostrando assim que o uso dessas espécies arbóreas melhoram a qualidade do solo.

Pereira et al. (2015) avaliaram o ganho de peso de bovinos de corte, em capim Marandu associado com amendoim forrageiro recebendo uma adubação com $120 \mathrm{~kg} \mathrm{de} \mathrm{N} \mathrm{ha}^{-1}$. Tendo a conclusão, que a adubação pode ser substituída pela associação com o amendoim forrageiro, sem ocorrer alteração no ganho de peso dos animais.

Segundo Calazans et al. (2016), as estirpes de rizóbios da Cratylia argentea, otimizou a incorporação de biomassa e nutrientes em sistemas produtivos no cerrado.

Hirai et al. (2015) avaliaram ganho de peso de novilhos levando em consideração o uso de pastagem de aveia branca, consorciado com a leguminosa ervilhaca (Vica sativa) e com suplementação energética. Os resultados utilizando suplementação energética foram superiores; porém, o uso de pastagem consociada com leguminosa mostrou-se relevante, trazendo bons resultados quando avaliado ao uso 
apenas da pastagem, e sendo uma boa alternativa para minimizar custos, quando a suplementação se torna de alto valor.

O consórcio entre gramíneas do gênero Cynodon (cv. tifton 85 e coastcross) com Arachis pintoi (amendoim forrageiro), foi avaliado quanto ao seu valor nutritivo por Fioreli et al. (2018), sendo concluído que o uso de leguminosas associados a gramíneas reduz o teor fibroso e aumenta o teor de proteína bruta da pastagem.

A avaliação das propriedades físicas do solo contendo capim tanzânia (Megathyrsus maximus), adubado com nitrogênio mineral ou consorciado com a leguminosa estilosantes 'Campo Grande' (Stylosanthes spp.) mostrou que a pastagem associada a leguminosa é uma alternativa viável para mantença e melhoramento das condições físicas do solo (Ferreira et al., 2018).

Muir et al. (2019) fizeram uma avaliação dos conhecimentos relacionados ao uso de leguminosas em áreas de pastagens da Caatinga e concluíram que o uso de leguminosas aumenta os níveis de proteína bruta das pastagens, assim como o nitrogênio, favorecendo a recuperação de áreas degradadas.

\section{Moringa (Moringa Oleifa Lamark)}

A Moringa oleifera L. é uma leguminosa forrageira que contribui para recuperação de áreas de pastagens degradadas, já que ela tem a capacidade de fixar o nitrogênio atmosférico do ar e incorporálo no interior da planta, assim como uma posterior transferência para as gramíneas que estão na área. Além de recuperação de áreas degradadas tem a capacidade de produzir grande quantidade de biomassa que se pode usar na alimentação animal. Originária do nordeste indiano, pertence à família Moringaceae (Olson \& Fahey, 2011), ordem Papaverales, gênero Moringa, contém quatorze espécies, sendo que a mais conhecida e cultivada é a Moringa olerifa Lamark (Anwar et al., 2007; Fahey, 2005). É uma planta arbórea, de crescimento rápido (Almeida et al., 2017), com boa adaptação a solos e climas áridos (Olson \& Fahey, 2011), assim como a seca. Apresenta reprodução cruzada, sua multiplicação ocorre por sementes ou muda (Anwar et al., 2007; Fahey, 2005).

No Brasil é conhecida como lírio branco e/ou quiabo-de-quina (Alves et al., 2005) e é utilizada para o tratamento de água, assim como para a produção de óleo, madeira, papel, combustível, é utilizada também como planta medicinal e como fonte de alimento assim como em sistemas agroflorestais (Santos et al., 2011).

No cenário agrícola, a moringa tem alto valor, pois associa-se aos organismos do solo, contribuindo para um sistema sustentável do agrossistema. Essa associação propicia a ciclagem de nutrientes, aumenta os teores de matéria orgânica do solo, melhora a estrutura do solo, assim como aumenta a concentração dos nutrientes do solo e a forma como as plantas o utilizam (Emmanuel et al., 2011), fatores esses benéficos para a obtenção de sistemas agrícolas mais sustentáveis (FAO, 2010).

\section{Esgoto sanitário}

\section{Cenário nacional de coleta e tratamento de esgoto sanitário}

Com o aumento da população, as cidades têm apresentado falhas na infraestrutura, principalmente quanto ao fornecimento de água potável, coleta e tratamento de esgoto sanitário, assim como a destinação correta dos resíduos desse tratamento.

Segundo a Agência Nacional de Águas (ANA, 2017) eram geradas 9,3 mil toneladas de esgoto por dia no Brasil, dos quais apenas 43\% (3,9 mil t) são coletados e tratados em Estações de Tratamento de Esgoto (ETEs), $12 \%$ (1,1 mil t) recebem tratamento individuais através de fossas sépticas, sendo assim, apenas 55\% (5 mil t) do esgoto produzido diariamente recebe tratamento adequado. Dos 45\% (4,1 mil t) restante, $18 \%$ (1,7 mil t) são coletados e não tratado e 27\% (2,4 mil t) não é ao menos coletado.

No Mato Grosso do Sul, 117,2 toneladas de esgoto são geradas por dia, sendo que $42 \%$ do esgoto é coletado e tratado, $15 \%$ tratado por fossa séptica, $1 \%$ apenas coletado e $42 \%$ não recebe aporte de esgoto adequado.

Na Figura 2, observa-se a porcentagem de coleta e tratamento de esgoto sanitário no Brasil e no estado de Mato Grosso do Sul no ano de 2017. 


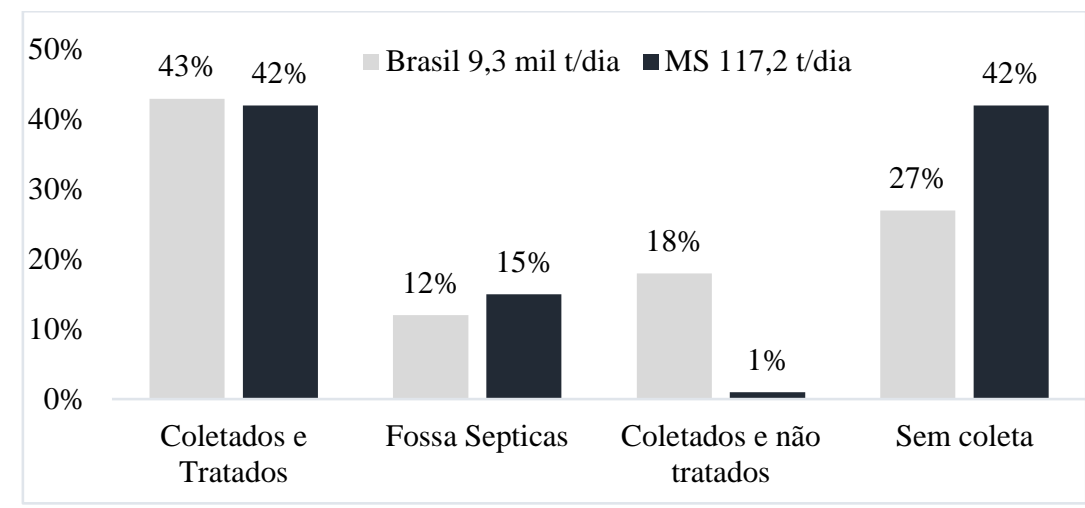

Figura 2. Coleta e tratamento de esgoto sanitário no Brasil e no estado de Mato Grosso do Sul, no ano de 2017. Fonte: Agência Nacional de Águas (2017).

De 2010 até 2018 o atendimento de redes de esgoto sanitário no Brasil cresceu 7,4\%, atingindo 60,9\% da população urbana, na região centro-oeste esse crescimento foi de $2,4 \%$ chegando a $58,2 \%$ da população urbana. Em 2010 o tratamento de esgoto sanitário era de 37,8\% do esgoto coletado no Brasil e 43,1\% na região centro-oeste, já em 2018 essa porcentagem subiu para 46,3\% e 53,9\% respectivamente.

A Figura 3 demonstra o crescimento de redes de esgotos e do tratamento de esgoto no Brasil e no Centro Oeste, de 2010 a 2018.

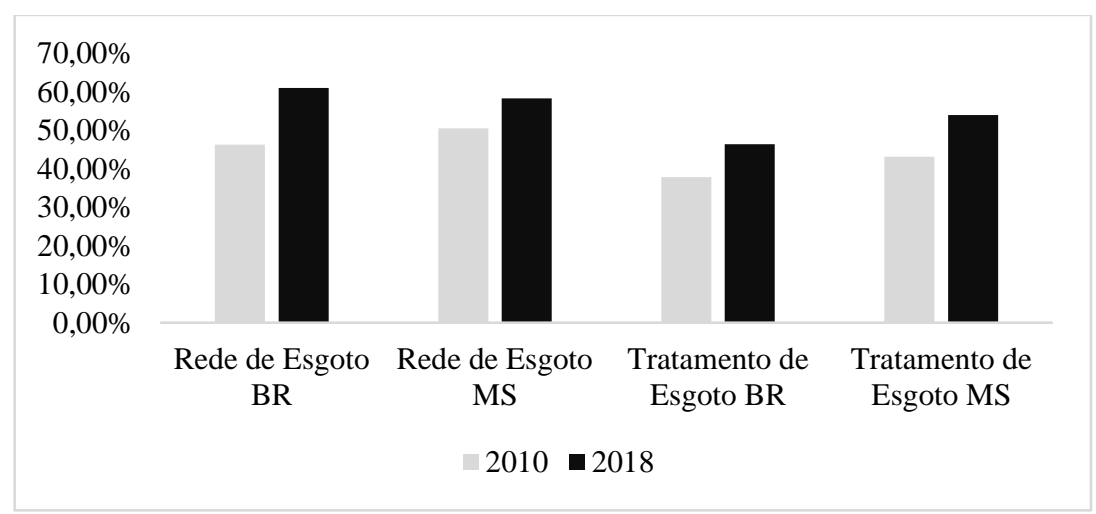

Figura 3. Crescimento de redes de esgotos e do tratamento de esgoto no Brasil e no Centro Oeste, de 2010 a 2018. Fonte: Sistema Nacional de Informação sobre Saneamento (2018).

\section{Tratamento do esgoto sanitário}

O tratamento de esgotos sanitários tem como objetivo a diminuição de matéria orgânica, microrganismos patógenos, materiais sólidos e nutrientes (Campos \& Alves, 2008) é realizado em 3 etapas: física, biológica e química ou tratamento primário, secundário e terciário respectivamente (ANA, 2017; Van Haandel \& Lettinga, 1994).

O tratamento físico ou primário é realizado por gradeamento, peneiramento, caixas separadoras, sedimentação e flotação, essa etapa ocorre a remoção do material mais grosseiro, sólidos sedimentáveis e materiais flutuantes, como areia, materiais fibrosos e lixo (ANA, 2017; Van Haandel \& Lettinga, 1994).

O processo biológico ou tratamento secundário é realizado pela atividade microbiana, tendo como objetivo a purificação das águas residuais, nessa etapa são removidos os materiais orgânicos e nutrientes, são diversos os meios de realizar esse processo, dentre eles: lagoas de estabilização, sistemas de lodos ativados e variantes, sistemas anaeróbios e sistemas aeróbios com leito fixo (ANA, 2017).

$\mathrm{Na}$ terceira etapa ocorre o tratamento químico, responsável por eliminar o excedente de nitrogênio e fósforo (ANA, 2017) ou até mesmo de organismos patogênicos (CASAN, 2012); porém, essa etapa é facultativa, dependendo do fluxo de cada estação de tratamento de esgoto (ETE). Na figura 4 há a demonstração das fases do tratamento do esgoto sanitário. 


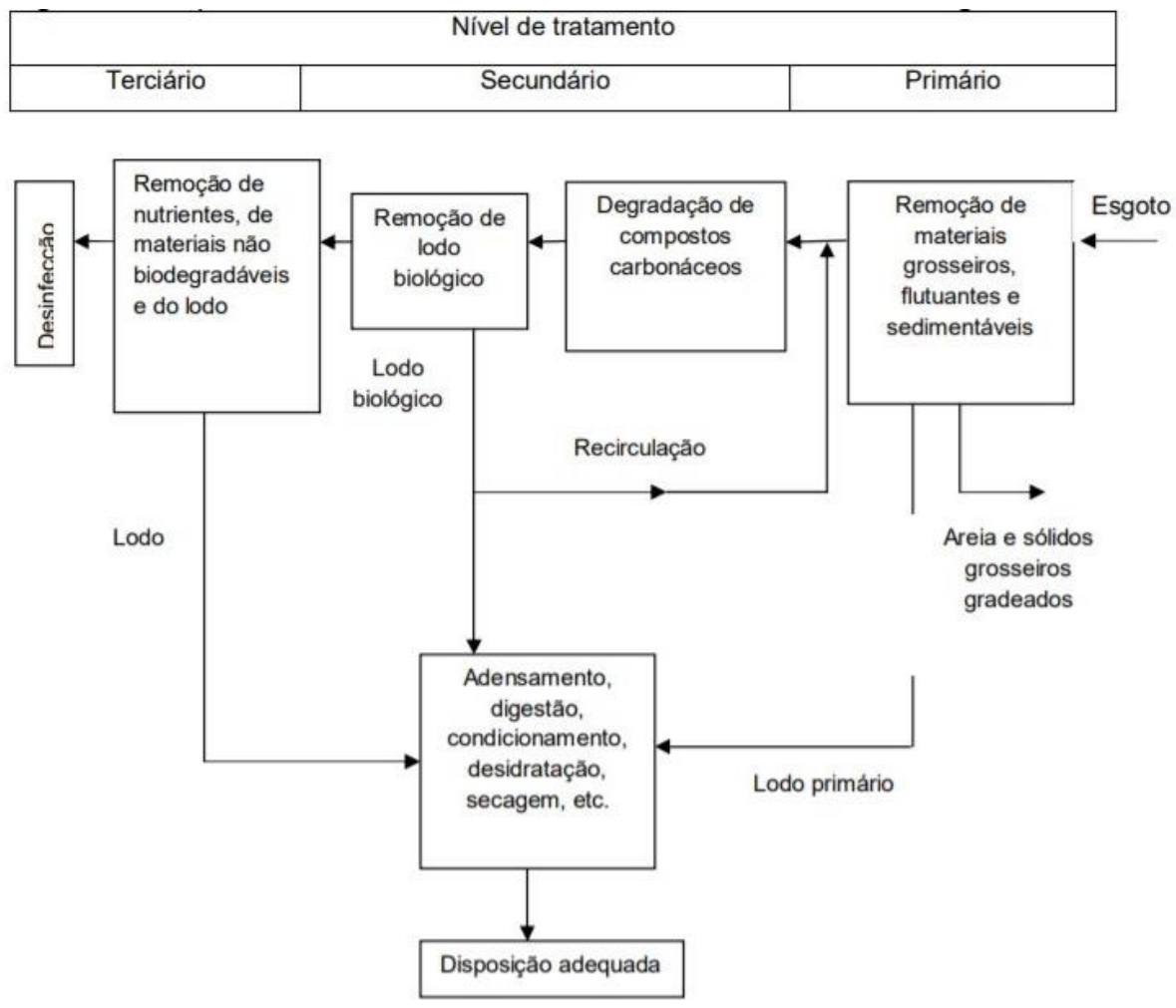

Figura 4. Fases do tratamento de esgoto sanitário. Fonte: Andrade \& Campo, 1999.

Após o tratamento do esgoto sanitário obtém-se subprodutos sólidos como: material gradeado, areia, escuma e lodo (Andreoli et al., 2014).

\section{Lodo de esgoto sanitário}

O lodo de esgoto (LE) é um dos subprodutos sólidos resultantes do tratamento dos esgotos sanitário. Esse lodo pode ser subdividido em lodo primário, secundário ou biológico e terciário ou químico e dependendo do tratamento pode-se obter o lodo misto. O lodo primário tem origem dos decantadores primários e é composto por sólidos sedimentáveis, já o lodo secundário nada mais é que os microrganismos que se desenvolveram durante a fase biológica do tratamento, em alguns sistemas o lodo primário e o secundário são misturados dando origem ao lodo misto. Já o lodo terciário ou químico ocorre apenas quando há o uso de produtos químico na fase de tratamento seja no tratamento primário ou quando o tratamento terciário é realizado (Andreoli et al., 2014).

\section{Tratamento do lodo de esgoto}

Após a produção de lodo de esgoto, o mesmo deve ser retirado do sistema e passar por um novo ciclo de tratamento antes da destinação final. As etapas desse tratamento são: adensamento, estabilização, condicionamento, desaguamento, higienização (Andreoli et al., 2014). O adensamento é a fase física do processo, onde há a redução de umidade e consequentemente do volume. A estabilização visa remover a matéria orgânica biodegradável do LE, assim há a redução dos odores. Para preparar o material para a fase de desaguamento, a fim de melhor aproveitar os sólidos nessa fase é adicionado produtos químicos ao LE, essa fase é denominada condicionamento. O desaguamento ou desidratação do lodo ocorre de forma manual ou mecânica, e tem como objetivo diminuir ainda mais o teor de umidade deixando-o próximo ao de componentes sólidos. A fase de higienização é realizada apenas se a destinação final do lodo for a reciclagem agrícola e consiste em diminuir a carga patogênica deste, após esse tratamento o LE é denominado biossólido.

\section{Composição do lodo de esgoto}

A qualidade e composição do LE é variável e depende da origem (domiciliar e/ou industrial), densidade populacional, hábitos sanitários, tipo de urbanização, condições ambientais, época do ano, perfil da saúde da população que o gera e tipo de tratamento submetido, dentre outros (Andrade et al., 
2006). O LE contém matéria orgânica, macronutrientes, micronutrientes, agentes patogênicos e metais pesados (Bettiol \& Camargo, 2006). Segundo Guimarães (2018) cerca de 70\% dos nutrientes são orgânicos (proteínas, carboidratos e gorduras) e 30\% inorgânicos (minerais, sais e metais).

\section{Contaminantes do lodo de esgoto}

Os principais contaminantes do lodo de esgoto são os metais pesados e os agentes patogênicos. Podemos identificar alguns metais pesados que podem ser encontrados no LE em maior ou menor quantidade, são eles, o arsênio, bário, cádmio, chumbo, cobre, cromo, mercúrio, molibdênio, níquel, selênio e zinco. A contaminação por metais pesados de solos que recebem o lodo de esgoto tem sido nula ou baixa, porém a preocupação ocorre quando esse uso é recorrente, podendo ter um acúmulo maior que ideal desses metais (Gomes et al., 2006; Nascimento et al., 2004). A interação dos metais pesados com o solo está intimamente ligada com o pH deste, sendo assim o ideal é que o pH do solo fique em torno de 5,5, evitando assim que a quantidade biodisponível de metais pesados seja prejudicial para plantas, animais ou ao ambiente (Guimarães, 2018).

A resolução do CONAMA no 375/2006 define a quantidade máxima de metais pesados presentes no LE para que esse possa ser depositado no solo (Tabela 1).

Tabela 1. Limites máximos de concentração de metais pesados conforme CONAMA 375/2006.

\begin{tabular}{lc}
\hline Metais Pesados & Quantidade máxima permitida $(\mathrm{mg} / \mathrm{kg}$ de base seca) \\
\hline Arsênio & 41 \\
Bário & 1300 \\
Cádmio & 39 \\
Chumbo & 300 \\
Cobre & 1500 \\
Cromo & 1000 \\
Mercúrio & 17 \\
Molibdênio & 50 \\
Níquel & 420 \\
Selênio & 100 \\
Zinco & 2800 \\
\hline
\end{tabular}

Fonte: Adaptado da Resolução CONAMA N³75/2006.

Os agentes patogênicos encontrados no biossólido são subdivididos em cinco grupos: helmintos, protozoários, fungos, vírus e bactérias. Esses patógenos podem ser oriundos de humanos, animais domésticos ou animais presentes nos esgotos (Andreoli et al., 2014). Visando a mitigação desses agentes patogênicos presentes no lodo de esgoto, o mesmo deve ser submetido a tratamentos que diminuam a taxa desses patógenos, segundo o a resolução $\mathrm{n}^{\circ} 375$ de 2006 do CONAMA os tratamentos que diminuem essa carga patogênica são: digestão aeróbia ou anaeróbia, estabilização alcalina, secagem térmica e compostagem. Nessa resolução fica definido as concentrações máximas desses agentes patogênicos presente no lodo e sua classificação (Tabela 2).

Tabela 2. Limites máximos de concentração de agentes patogênicos conforme a classe do composto.

\begin{tabular}{ll}
\hline Classe do lodo & Concentração de patógenos \\
\hline A & Coliformes termotolerantes $<10^{3} \mathrm{NMP} / \mathrm{g}$ de ST, Ovos viáveis de helmintos $<0,25$ ovo/g de ST, Salmonella \\
B & ausência de $10 \mathrm{~g}$ de ST, Vírus $<0,25 \mathrm{UFP}$ ou UFF/g de ST \\
Coliformes termotolerantes $<106 \mathrm{NMP} / \mathrm{g}$ de ST, Ovos viáveis de helmintos $<10$ ovos/g de ST
\end{tabular}

ST: Sólidos Totais; NMP: Número Mais Provável; UFF: Unidade Formadora de Foco; UFP: Unidade Formadora de Placa; Fonte: Adaptado da Resolução CONAMA N³75/2006.

\section{Nutrientes presentes no biossólido}

No lodo de esgoto há a presença de macronutrientes como o nitrogênio, fósforo e em menor quantidade o potássio, assim como micronutrientes (boro, cloro, cobre, ferro, manganês, molibdênio e 
zinco), além de ser riquíssimo em matéria orgânica (Andreoli et al., 2014; Bettiol \& Camargo, 2006; Guimarães, 2018).

\section{Destinação final do lodo de esgoto}

A disposição final do lodo de esgoto é de suma importância, sendo uma das etapas mais problemáticas do ciclo (Bettiol \& Camargo, 2006), a disposição inadequada desse resíduo traz sérios problemas ambientais e a saúde pública através da contaminação do lençol freático, da água e do solo (Rocha et al., 2013). Os custos com a destinação final do lodo de esgoto podem representar de $20 \%$ até $60 \%$ do custo de tratamento de esgoto, muitas vezes a forma de disposição final é feita de forma errônea, principalmente em países ainda em desenvolvimento como o caso do Brasil (Andreoli et al., 2014).

Há muitas formas de destinação final para esse lodo, dentre elas podemos destacar o aterro sanitário, land farming, reciclagem agrícola, uso na construção civil, incineração com aproveitamento energético. A maior parte do lodo de esgoto produzido no Brasil tem como forma de disposição final os aterros sanitários (Lobo et al., 2013; Rocha et al., 2013). Avaliando de forma sustentável as ETE's devem optar por tratamento de esgoto que produzam menores quantidade de lodo de esgoto, produzir um lodo de boa qualidade afim de gerar um lodo com menor índice de contaminantes viabilizando assim seu reuso, principalmente na agricultura. Dessa forma a destinação final em aterros sanitários ou em land farming ocorra apenas para lodos com alto índice de contaminantes (Andreoli et al., 2014).

O aproveitamento agrícola do lodo de esgoto tem sido uma das melhores maneiras de disposição final, pois é benéfica do ponto de vista econômico, ambiental e sociocultural (Bertanza et al., 2016). O lodo de esgoto na agricultura pode ser utilizado como fertilizante, sendo assim diminui a necessidade de extração de minérios que compõem os adubos minerais encontrados no mercado, aliando a preservação ambiental e o desenvolvimento agrícola (Dynia et al., 2006; Matos \& Matos, 2017), além de aumentar a produtividade das diversas culturas em que pode ser empregado (Lobo et al., 2013; Rocha et al., 2013).

Todavia, além dos benefícios a deposição do LE em solos agrícolas pode causar problemas relacionados à presença de patógenos e metais pesados em sua composição, o que pode contaminar o solo e a produção, trazendo riscos ao homem (Gomes et al., 2006). Para evitar esses danos a Resolução do Conselho Nacional do Meio Ambiente - CONAMA nº 375/2006, normatiza essa utilização desses resíduos em solo agrícola.

\section{Resolução CONAMA $n^{\circ} 375 / 2006$}

Essa resolução regulamenta o uso do lodo de esgoto na agricultura estabelecendo critérios para sua aplicação de forma a evitar efeitos adversos ao meio ambiente e a saúde pública. Dentre as recomendações contidas na resolução podemos destacar os seguintes critérios: classificação do Lodo (A e B) e onde cada um pode ser utilizado, necessidade de projeto agronômico, quantidade do biossólido a ser aplicado, declividade da área a qual o LE vai ser aplicado, distancia de nascentes e rios, espécies vegetais a serem beneficiadas, tempo de vazio sanitário da área após a aplicação, teores de metais pesados permitidos, taxa de mineralização do LE, níveis de microrganismos patógenos, dentre outros pontos importantes para a utilização desse resíduo como fonte de adubo orgânico (CONAMA, 2006). A resolução normatiza toda e qualquer aplicação do biossólido na agricultura, sendo assim deve ser consultada na integra para a elaboração de qualquer projeto nessa área.

\section{Uso do lodo de esgoto na agricultura}

Muitos são os relatos de benefícios do uso do LE na agricultura, entre eles podemos citar:

Campos \& Alves (2008) citam o LE como um fertilizante orgânico capaz de aumentar a produtividade de diversas culturas. Assim como Guimarães (2018), além de descrever as propriedades de micro e macronutrientes que LE, fornece para as culturas, demonstram também sua capacidade de melhoria na qualidade do solo, aumentado a CTC do solo e reduzindo as concentrações de alumínio trocável. Pode ser utilizado também como condicionador de solo, melhorando a agregação de partículas do solo, tornando-o mais aerado e com maior capacidade de retenção de água. Assim como aumentar os microrganismos presentes no solo, melhorando físico e biologicamente esse solo (Guimarães, 2018). 
Maia et al. (2018) relatam que a reciclagem do LE como adubo orgânico é uma ótima alternativa, pois além de produzir um adubo de ótima qualidade diminui os impactos ambientais. A comparação entre o adubo mineral e o LE para a produção de mudas de flores foi avaliada por Faustino et al. (2021), como resultado pode-se observar que o LE como fonte de adubo respondeu todas as exigências da cultivar, se mostrando uma ótima fonte para produção de substrato.

Ao testar o LE em diferentes processos de estabilização na cultura do girassol, Nascimento et al. (2014) concluíram que tanto o lodo de esgoto solarizado quanto caleado aumentam o teor de proteína bruta do solo e não há alteração de metais pesados na folha ou pecíolo da cultivar. Silva et al. (2015b) descrevem a utilização de biossólido como substrato para a produção de mudas, diminuindo os custos de produção e preservando o meio ambiente. Na cultura do café temos relatos de Martins et al. (2005) demonstrando resultados positivos, indicando o uso do LE como condicionador de solo para a cultura do café.

Em Jaboticabal-SP, foram avaliadas as características químicas e bioquímicas de dois latossolos vermelhos (um distrófico e outro eutroférrico), que receberam diferentes doses de lodo de esgoto por 16 anos, onde era realizado o cultivo de milho. Na área havia os seguintes tratamentos: T1: com fertilizante mineral, T2: $5 \mathrm{mg} / \mathrm{ha}$ de LE, T3: 10mg/ha de LE e T4: $20 \mathrm{mg} / \mathrm{ha}$ de LE. As parcelas onde foi aplicado o LE tiveram aumento de fósforo em ambos os solos e matéria orgânica no solo distrófico. A dose com melhores repostas foi a de $20 \mathrm{mg} / \mathrm{ha}$, ocasionando aumento da atividade da fosfatase ácida no $\mathrm{s}$. eutroférrico e aumento da respiração basal e coeficiente metabólico no s. distrófico. Assim como aumento na produtividade de grãos de milho sem causar fitotoxidade ou deficiência de nutrientes nas plantas cultivadas na área (Yada et al., 2015).

Zuba et al. (2015) avaliaram o teor de matéria orgânica, pH, soma de bases, CTC efetiva, CTC potencial, saturação por base e a acidez potencial de um solo cultivado com mamona utilizando como fonte de adubo silicato de cálcio e magnésio (SCM) e LE nas seguintes doses: SCM 0 e 1 t/ha- 1 e LE 0; 23,81; 47,62 e 71,43 t/ha ${ }^{-1}$. Ambos os tratamentos não alteraram os atributos edáficos do solo. $\mathrm{O}$ tratamento com SCM não demonstrou modificações no solo; porém, a adubação de LE reduziu o pH do solo, aumentou a matéria orgânica e a capacidade de troca catiônica, tendo melhores resultados na dose de 71,43 t $/ \mathrm{ha}^{-1}$ do lodo.

Goçalves Júnior et al. (2015) avaliaram a fito disponibilidade de metais pesados no milho cultivado com diferentes doses de LE $(0 ; 10,0 ; 20,0 ; 40,0$ e 60,0 mg/há), sem adubo e com fertilizante mineral $\mathrm{N}: \mathrm{P} 2 \mathrm{O} 5: \mathrm{K} 2 \mathrm{O}$. Após 45 dias do nascimento das plantas as mesmas foram colhidas e avaliadas para metais pesados: $\mathrm{Cu}, \mathrm{Zn}, \mathrm{Fe}, \mathrm{Mn}, \mathrm{Cd}, \mathrm{Pb}$ e $\mathrm{Cr}$. Como resultado apenas $\mathrm{Zn}$ aumentou conforme aumentava-se a dose de LE, não houve detecção de teores fito tóxicos dos metais pesados avaliados na cultivar, assim foi concluído que apenas uma aplicação de LE não causa translocação de metais pesados a planta.

D'Ávila et al. (2016) cultivaram capim-limão com 0, 5, 10, 20, 40 e 60 t/ha ${ }^{-1}$ de lodo de esgoto e resíduos de poda de vegetação urbana e analisaram ao final as concentrações de nutrientes nas plantas, os teores de clorofila, número de perfilhos, produção de biomassa, óleo essencial e a qualidade microbiológica das folhas. $\mathrm{O}$ uso do LE associado os resíduos de poda teve efeito positivo aumentando os teores de nutrientes das plantas, principalmente nitrogênio, obtendo maior produção dos itens avaliados. Além de melhorar a fertilidade do solo, o uso do bissólido favorece a fixação de carbono no solo, sendo assim a uma redução da contaminação ambiental, sendo altamente benéfico para sistemas agrosilvipastoris (Heimersson et al., 2017).

No estado do Paraná entre os anos de 2011 e 2013 foi realizado um levantamento do uso agrícola do LE, onde foram analisados relatórios de rastreabilidade, projetos agronômicos e laudos laboratoriais de 129 lotes do lodo, onde verificou-se que 107.416 t foram aplicadas em 5.529 há de áreas agrícolas no Paraná, a maior concentração de utilização foi na região metropolitana de Curitiba, mesmo sendo no interior a maior concentração de áreas agrícolas, porém ainda com menor uso desse tipo de adubação (Bittencourt et al., 2017).

Barbosa et al. (2017) utilizaram LE alcalinizado e avaliaram como este afeta a fertilidade de solos ácidos. Foram incubadas amostradas de solo ácidos por 60 dias junto a doses de LE nas concentrações de $0,10,20,40$, e $80 \mathrm{mg} / \mathrm{ha}^{-1}$ e outras amostras com as mesmas doses de calcário. O LE se mostrou superior ao calcário para a correção da acidez do solo, assim como no aumento da disponibilidade de $\mathrm{P}$, $\mathrm{Ca}^{2+}, \mathrm{Mg}^{2+}$ em todos os solos, $\mathrm{K}^{+}$em sete dos solos e C orgânicos em três solos. Pode-se observar 
também que solos muito argilosos suportam maiores doses do lodo quando comparado aos de menor teor de argila. Assim o uso desse tipo de adubação corrige acidez do solo, aumenta a fertilidade e gera economia para o agricultor. Seguindo esse mesmo padrão de incubação e dosagem de lodo de esgoto, Dalpisol et al. (2017) avaliaram a disponibilidade de $\mathrm{Zn}, \mathrm{Cu}$ e $\mathrm{Mn}$ no solo adubados com LE alcalinizado, obtendo os seguintes resultados: aumento na disponibilidade de $\mathrm{Zn}$ e diminuição na de $\mathrm{Mn}$, o $\mathrm{Cu}$ aumentou em solos de argila média e diminuiu em solos muito argilosos, em solos com pH ideal ou próximo a esse o uso do LE alcalinizado deve ser realizado com cautela para que o $\mathrm{pH}$ não aumente excessivamente e cause desbalanço nos nutrientes.

Salgado et al. (2018) utilizaram o esgoto doméstico tratado como fonte de adubação para a produção de melancia tipo Crimson Sweet no Sertão de Pernambuco. Foi avaliado a aplicação de 4 lâminas de irrigação $(50,75,100$ e 125\%), em todos os tratamentos obteve-se a melhoria da capacidade de troca catiônica do solo, assim como a redução do seu pH. No tratamento com $125 \%$ houve a produção de frutos maiores e maior produtividade da cultura, mostrando assim que o uso dessa fonte de adubação é viável para essa cultura e para o solo.

Knopik et al. (2018) também fizeram uma análise da utilização agrícola do LE no estado do Paraná. Dessa vez o estudo foi realizado na região de Campo Mourão entre 2012 e 2016 e foram avaliados 15 lotes de lodo, totalizando 5.244t, utilizados por 14 produtores em uma área de aproximadamente 482 ha, onde foram aplicado em média $7 \mathrm{t} / \mathrm{ha}^{-1}$ de LE proporcionando ao solo $912 \mathrm{~kg} / \mathrm{ha}^{-1}$ de carbono orgânico, $582 \mathrm{~kg} / \mathrm{ha}^{-1}$ de cálcio total, $160 \mathrm{~kg} / \mathrm{ha}^{-1}$ nitrogênio total, $143 \mathrm{~kg} / \mathrm{ha}^{-1}$ de magnésio, $24 \mathrm{~kg} / \mathrm{ha}^{-1}$ de fósforo, $22 \mathrm{~kg} / \mathrm{ha}^{-1}$ de enxofre, $6 \mathrm{~kg} / \mathrm{ha}^{-1}$ de sódio, $4 \mathrm{~kg} / \mathrm{ha}^{-1}$ de potássio e de $2,15 \mathrm{~kg} / \mathrm{ha}^{-1}$ zinco e 0,76 $\mathrm{kg} / \mathrm{ha}$ de cobre. $\mathrm{O}$ aporte desses nutrientes evitou o uso de fertilizantes minerais, causando uma economia ao produtor de $\mathrm{R} \$ 539,56$. Esses dados demonstram a eficácia do LE como adubo orgânico, levando a reciclagem de materiais poluentes e minimizando custos com fertilizantes.

A produção de mudas de A. sellowiana também foram objeto de estudo com o uso de biossólido como fonte de substrato em diferentes doses e associada a outros composto orgânicos (vermiculita e os resíduos fibra de coco, palha de café in natura, esterco bovino não curtido e palha de café in natura, casca de arroz carbonizada e casca de arroz in natura, nas proporções de 100:0, 80:20, 60:40, 40:60 e 20:80 (lodo de esgoto:materiais) obtendo bons resultados nas proporções de 20 e $40 \%$ do LE para 80 e $60 \%$ de compostos orgânico (Caldeira et al., 2018).

Em Janaúba-MG, Mota et al. (2018) avaliaram o uso do biossólido como adubo na cultura do abacaxi vs. adubo mineral, foram utilizadas cinco variedade de abacaxizeiro e mensurado teor de nutrientes no fruto e no solo, assim como contaminação do fruto e solo. Os frutos adubados com o biossólido tiveram maior teor de zinco e o solo maiores teores de Zinco e cobre. Assim como os frutos que receberam essa adubação não demonstraram contaminação microbiológica acima da estabelecida na legislação.

Costa et al. (2019) avaliaram o crescimento e a produtividade do milho no Piauí, foram utilizadas três fontes de adubo: biossólido (0,1,2 e $4 \mathrm{~kg} /$ parcela), adubo mineral (100 g/parcela) e esterco bovino (200 g/parcela). As avaliações foram realizadas conforme alguns parâmetros: germinação e crescimento do milho, tamanho das espigas, produtividade de grãos e biomassa seca da parte aérea (BSA), assim como biomassa seca total (BST). O uso do biossólido aumentou todos os parâmetros avaliados, tendo melhor desempenho quando comparado ao adubo mineral e ao esterco bovino.

D’Ávila et al. (2016) avaliaram financeiramente a disposição final do LE, utilizando os seguintes cenários: Estação de Tratamento que destina os resíduos sólidos produzidos para aterro sanitário e Estação de Tratamento que beneficia o lodo de esgoto, por meio do processo de compostagem para a produção de adubo, foram avaliados os diversos custos em uma estação de tratamento com capacidade média de $3.356 \mathrm{~m} 3$ de esgoto por dia. Foi levado em consideração infraestrutura, mão de obra, custos de manutenção e licenciamentos necessários para o funcionamento para as análises. As estações que beneficiam o LE para o uso agrícola têm uma rentabilidade maior que as que destinam para aterros sanitários, cerca de $61,6 \%$ ao ano.

\section{Uso de biossólido no processo de recuperação de pastagens}

O uso de resíduos orgânicos pode substituir a utilização de adubos químicos, diminuindo os altos custos com esses adubos ( $\underline{\text { Silva et al., 2013) }}$. A adubação orgânica melhora a qualidade física e biológica 
do solo, aumenta a retenção de água, fornece nutrientes ao solo, garantindo a nutrição das plantas (Finatto et al., 2014; Penteado, 2007; Silva et al., 2013).

Visto isso, o uso de lodo de esgoto como fonte de adubo orgânico é benéfico para a recuperação de pastagens, já que esse resíduo fornece uma ampla gama de macro e micro nutrientes ao solo e as plantas, aumentando a produtividade dessas, aumenta a CTC do solo e sua agregação de partículas, aumentando assim a aeração do solo (Campos \& Alves, 2008; Pedroza et al., 2010; Siqueira et al., 2019). Além dos benefícios ao solo o uso do lodo de esgoto diminui a necessidade do uso de adubos químicos e de sua extração, aumentando assim os benefícios financeiros e ambientais (Dynia et al., 2006; Matos \& Matos, 2017). Há uma escassez de dados do uso de biossólido como fonte de adubação para pastagens, sendo assim pesquisas relacionadas a esse tema são de suma importância para o entendimento e melhoramento dessa utilização. Alguns dados obtidos nos últimos anos estão listados á baixo.

O uso do biossólido como fonte de adubo foi avaliado na implantação da Urochloa brizantha cv. Marandu por Resende Júnior (2015) que concluiu que o uso do biossólido deve ser associado a adubação mineração para obtenção de melhores resultados (número de perfilhos, altura, clorofila a e b, massa seca e fresca, área foliar e teor foliar do capim Marandu), pois quando avaliados separadamente os adubos minerais demonstram melhores resultados. Resende Júnior (2015) relata também que o uso do biossólido caleado na implantação de pastagens, demonstra propriedades corretivas do solo a curto prazo, já que o mesmo aumenta os níveis de $\mathrm{pH}$ e porcentagem de saturação de base do solo.

Neves (2017) avaliou o uso de biossólido como fonte de adubação para o capim Elefante, levando em consideração a produção e ganho energético da pastagem, contaminação do solo, ganhos físicoquímico do solo e emissão de gases. Os dados obtidos nesse estudo mostram que a produção de pastagem utilizando biossólido é similar ao uso de fertilizante químico, assim como não há alteração no ganho energético para seu uso na nutrição animal. Quanto a contaminação do solo, Neves (2017) não observou níveis anormais de nitrogênio, microrganismos patógenos ou metais pesados. A avaliação do ciclo de vida (ACV) mostrou que os tratamentos com biossólido produziram 32,4\% a mesmo de $\mathrm{CO}_{2} \mathrm{eq}$, demostrando assim que o uso de biossólido como fonte de adubação para o capim Elefante produz efeito satisfatório e pode substituir o adubo químico.

Alvarenga et al. (2018) avaliaram a produção de biomassa e a fito extração de Cu e $\mathrm{Zn}$ pelo capimelefante produzido em lodo de esgoto puro, onde concluiu que o uso do lodo de esgoto puro proporciona uma alta e rápida produção de biomassa vegetal e o capim demonstra baixo percentual de fito extração de $\mathrm{Cu}$ e $\mathrm{Zn}$ do lodo.

\section{Considerações finais}

$\mathrm{O}$ uso de tecnologias que permitam reestabelecer a qualidade e produtividade das pastagens, diminuam os custos desse processo e preservem o meio ambiente se faz cada vez mais necessário, com isso o uso do biossólido e da Moringa oleífera mostra-se uma alternativa viável para o processo de recuperação de pastagens.

\section{Referências bibliográficas}

Aguirre, P. F., Olivo, C. J., Simonetti, G. D., Nunes, J. S., Silva, J. O., Santos, M. S., \& Anjos, A. N. A. (2014). Produtividade de pastagens de Coastcross-1 em consórcio com diferentes leguminosas de ciclo hibernal. Ciência Rural, 44(12), 2265-2272.

Almeida, C. B. L., Conde, C., Carvalho, R. C. D., \& Almeida, E. S. (2017). Estudo prospectivo da moringa na indústria de cosméticos. Cadernos de Prospecção, 10(4), 905. https://doi.org/10.9771/cp.v10i4.23060.

Alvarenga, A. C., Cardoso, P. H. S., Coutinho, M. A. N., Oliveira, A. L. G., \& Sampaio, R. A. (2018). Produção de biomassa e fitoextração de cu e zn pelo capim-elefante cultivado em lodo de esgoto puro. Revista Engenharia Na Agricultura, 26(5), 473-482.

Alves, M. C. S., Medeiros Filho, S., Bezerra, A. M. E., \& Oliveira, V. C. (2005). Seed germination and seedling development of Moringa oleifera L. under different environments and submitted to presoaking. Ciência e Agrotecnologia, 29(5), 1083-1087. 
ANA - Agência Nacional de Águas. Atlas Esgotos: Despoluição de Bacias Hidrográficas. Brasilia, 2017. Disponível em: http://atlasesgotos.ana.gov.br. Acesso em 05/abril/2019.

Andrade, C. A., Oliveira, C., \& Cerri, C. C. (2006). Cinética de degradação da matéria orgânica de biossólidos após aplicação no solo e relação com a composição química inicial. Bragantia, 65, 659-668.

Andreoli, C. V, Fernandes, F., \& Von Sperling, M. (2014). Lodo de esgoto: Tratamento e disposição final. DESA, 483.

Anwar, F., Latif, S., Ashraf, M., \& Gilani, A. H. (2007). Moringa oleifera: a food plant with multiple medicinal uses. Phytotherapy Research, 21(1), 17-25.

Assis, P. C. R., Stone, L. F. M., Oliveira, J., Wruck, F. J., Madari, B. E., \& Heinemann, A. B. (2019). Atributos físicos, químicos e biológicos do solo em sistemas de integração lavoura-pecuária-floresta. Agrarian, 12(43), 57-70. https://doi.org/10.1590/1807-1929/agriambi.v19n4p309-316.

Ázcon-Aguilar, C. A., \& Barea, J. M. (1978). Effects of interactions between different culture fractions of'phosphobacteria' and Rhizobium on mycorrhizal infection, growth, and nodulation of Medicago sativa. Canadian Journal of Microbiology, 24(5), 520-524.

Barbosa, J.Z., Poggere, G. C., Dalpisol, M., Serrat, B. M., Bittencourt, S., \& Motta, A. C. V. (2017). Alkalinized sewage sludge application improves fertility of acid soils. Ciência e Agrotecnologia, 41, 483-493.

Barcellos, A. O., Ramos, A. K. B., Vilela, L., Junior, M., \& Bueno, G. (2008). Sustentabilidade da produção animal baseada em pastagens consorciadas e no emprego de leguminosas exclusivas, na forma de banco de proteína, nos trópicos brasileiros. Revista Brasileira de Zootecnia, 37(Supl.), 51-67.

Bernardino, F. S., \& Garcia, R. (2009). Sistemas silvipastoris. Pesquisa Florestal Brasileira, 60, 77-87.

Bertanza, G., Baroni, P., \& Canato, M. (2016). Ranking sewage sludge management strategies by means of Decision Support Systems: A case study. Resources, Conservation and Recycling, 110, 1-15. https://doi.org/10.1016/j.resconrec.2016.03.011.

Bettiol, W., \& Camargo, O. A. (2006). A disposição de lodo de esgoto em solo agrícola. Embrapa Meio Ambiente.

Bittencourt, S., Aisse, M. M., \& Serrat, B. M. (2017). Gestão do uso agrícola do lodo de esgoto: estudo de caso do estado do Paraná, Brasil. Engenharia Sanitaria e Ambiental, 22, 1129-1139.

BRASIL, Ministério da Agricultura, Pecuária e Abastecimento. Plano Setorial de Mitigação e de Adaptação às Mudanças Climáticas para a Consolidação de uma Economia de Baixa Emissão de Carbono na Agricultura. Brasília: Ministério da Agricultura, Pecuária e Abastecimento. 173 p. 2012.

Calazans, G. M., Oliveira, C. A., Cruz, J. C., Matrangolo, W. J. R., \& Marriel, I. E. (2016). Selection of efficient rhizobial symbionts for Cratylia argentea in the cerrado biome. Ciência Rural, 46(9), 15941600. https://doi.org/10.1590/0103-8478cr20151137.

Caldeira, M. V. W., Santos, F. E. V, Kunz, S. H., Klippel, V. H., Delarmelina, W. M., \& Gonçalves, E. O. (2018). Solid urban waste in the production of Aegiphila sellowiana Cham. seedlings. Revista Brasileira de Engenharia Agrícola e Ambiental, 22, 831-836.

Campos, F. S., \& Alves, M. C. (2008). Uso de lodo de esgoto na reestruturação de solo degradado. Revista Brasileira de Ciência Do Solo, 32, 1389-1397. https://doi.org/10.1590/s0100-06832008000400003.

CASAN. Companhia Catarinense de Águas e Saneamento. ETE- Estações de Tratamento de Esgotos Sanitários. Florianópolis, 2012. Disponível em: < http://novo.casan.com.br/menuconteudo/index/url/ete-estacao-de-tratamento-deesgotos-sanitarios\#600>. Acesso em: maio de 2020.

Carvalho, W. T. V., Minighin, D. C., Gonçalves, L. C., Villanova, D. F. Q., Mauricio, R. M., \& Pereira, R. V. G. (2017). Pastagens degradadas e técnicas de recuperação: Revisão. PUBVET, 11, 947-1073. https://doi.org/10.22256/pubvet.v11n10.1036-1045.

CONAMA - Conselho Nacional do Meio Ambiente. Define critérios e Companhia de Saneamento de Goiás - SANEAGO. Operação de Estação de Tratamento de Esgoto. Manual de operações de Estação de Tratamento de Esgoto, 2015.

Cordeiro, L. A. M., Vilela, L., Marchão, R. L., Kluthcouski, J., \& Júnior, G. B. M. (2015). Integração lavoura-pecuária e integração lavoura-pecuária-floresta: estratégias para intensificação sustentável do uso do solo. Cadernos de Ciência \& Tecnologia, 32(1/2), 15-53. https://doi.org/http://seer.sct.embrapa.br/index.php/cct/article/view/23294/13157. 
Costa, N. L. (1995). Adubação nitrogenada e consorciação de capim-elefante (Pennisetum purpureum cv. Cameroon) com leguminosas forrageiras tropicais. Pesquisa Agropecuária Brasileira, 30(3), 401-408.

Costa, T. G. A., Cunha, L. M., de Freitas Iwata, B., Coelho, J. V., Santos, J. G. P., \& Clementino, G. E. S. (2019). Avaliação do crescimento de milho (Zea mays L.) sobre o efeito de diferentes doses de biossólido em latossolo vermelho-amarelo no cerrado piuense. Multi-Science Journal (ISSN 2359-6902), 2(1), 1-6.

D’Ávila, J. V, Martinazzo, A. P., Santos, F. S., Teodoro, C. E. S., \& Portz, A. (2016). Essential oil production of lemongrass (Cymbopogon citratus) under organic compost containing sewage sludge. Revista Brasileira de Engenharia Agrícola e Ambiental, 20, 811-816.

Dalpisol, M., Serrat, B. M., Motta, A. C. V., Poggere, G. C., Bittencourt, S., \& Barbosa, J. Z. (2017). Zinc, copper and manganese availability in soils treated with alkaline sewage sludge from Paraná state (Brazil). Ciência e Agrotecnologia, 41, 81-93.

Dias-Filho, M. B. (2003). Degradação de pastagens. EMBRAPA, 319.

Diehl, M. S., Olivo, C. J., Agnolin, C. A., Junior, R. L. de A., Bratz, V. F., \& Santos, J. C. (2014). Forage yield and nutritive value of Elephant grass, Italian ryegrass and spontaneous growing species mixed with forage peanut or red clover. Ciência Rural, 44(10), 1845-1852. https://doi.org/10.1590/0103-8478cr20131347

Dynia, J. F., Souza, M. D., \& Boeira, R. C. (2006). Lixiviação de nitrato em Latossolo cultivado com milho após aplicações sucessivas de lodo de esgoto. Pesquisa Agropecuária Brasileira, 41(5), 855862. https://doi.org/10.1590/s0100-204x2006000500019.

Emmanuel, S. A., Emmanuel, B. S., Zaku, S. G., \& Thomas, S. A. (2011). Biodiversity and agricultural productivity enhancement in Nigeria: application of processed Moringa oleifera seeds for improved organic farming. Agriculture and Biology Journal of North America, 2(5), 867-871. https://doi.org/10.5251/abjna.2011.2.5.867.871.

FAO - Organização das Nações Unidas para a Alimentação e a Agricultura. Soil Biota and Biodiversity: "The "Root" of Sustainable Development". 2010. Disponível em: http://www.fao.org/tempref/docrep/fao/010/i0112e/i0112e07.pdf.. Acesso em: 15/05/2019.

Fahey, J. W. (2005). Moringa oleifera: A Review of the medical evidence for its nutritional, therapeutic, and prophylactic properties. Part 1. Trees for Life Journal, 1(5), 1-24.

Faria, E. F. (2014). Efeito do sistema de integração pecuária-floresta na recuperação de larvas infectantes de nematoides tricostrongilídeos de ovinos: Vol. PhD. Universidade Federal de Mato Grosso.

Faustino, R., Kato, M. T., Florêncio, L., \& Gavazza, S. (2021). Lodo de esgoto como substrato para produção de mudas de Senna siamea Lam. Revista Brasileira de Engenharia Agrícola e Ambiental, 9, 278-282.

Ferraz, J. B. S., \& Felício, P. E. (2010). Production systems - An example from Brazil. Meat Science, 84(2), 238-243. https://doi.org/10.1016/j.meatsci.2009.06.006.

Ferreira, C. J. B., Tormena, C. A., Cecato, U., Franco, H. H. S., Moreira, W. H., Galbeiro, S., \& Ribeiro, O. L. (2018). Soil physical properties under a'Tanzânia'grass pasture fertilized with mineral nitrogen or intercropped with stylosanthes. Pesquisa Agropecuária Brasileira, 53(4), 478-486. https://doi.org/10.1590/S0100-204X2018000400009.

Finatto, J., Altmayer, T., Martini, M. C., Rodrigues, M., Basso, V., \& Hoehne, L. (2014). A importância da utilização da adubação orgânica na agricultura. Revista Destaques Acadêmicos, 5(4), 85-93.

Fioreli, A. B., Ziech, M. F., Fluck, A. C., Gerei, J. C., Col, D., Berns, L., Hoffmann, F., \& Costa, O. A. D. (2018). Valor nutritivo de gramíneas do gênero Cynodon consorciadas com amendoim forrageiro. Arquivo Brasileiro de Medicina Veterinária e Zootecnia, 70, 1970-1978. https://doi.org/10.20906/cps/sicite2015-0178

Freitas, E. C. S., Oliveira Neto, S. N., Fonseca, D. M., Santos, M. V., Leite, H. G., \& Machado, V. D. (2013). Deposição de serapilheira e de nutrientes no solo em Sistema Agrossilvipastoril com eucalipto e acácia. Revista Árvore. Revista Árvore, 37(3), 409-419. https://doi.org/http://dx.doi.org/10.1590/S0100-67622013000300004.

Goçalves Júnior, A. C., Nacke, H., Schwantes, D., Coelho, G. F., Sousa, R. F. B., \& Parizotto, A. A. (2015). Fitodisponibilidade de metais em milho (Zea mays) cultivado com aplicação de biossólido. Revista de Ciências Agrárias, 38(1), 71-78. 
Gomes, S. B. V., Nascimento, C. W. A., Biondi, C. M., \& Accioly, A. M. A. (2006). Distribuição de metais pesados em plantas de milho cultivadas em Argissolo tratado com lodo de esgoto. Ciência Rural, 36(6), 1689-1695. https://doi.org/10.1590/s0103-84782006000600004.

Guimarães, J. C. S. (2018). Utilização do lodo de esgoto na agricultura: uma análise cienciométrica. Research, Society and Development, 7(9), 1-31. https://doi.org/10.17648/rsd-v7i9.391.

Heimersson, S., Svanström, M., Cederberg, C., \& Peters, G. (2017). Improved life cycle modelling of benefits from sewage sludge anaerobic digestion and land application. Resources, Conservation and Recycling, 122, 126-134.

Hirai, M. M. G., Menezes, L. F. G., Kuss, F., Paris, W., Lisbinski, E., Oliveira, O. N., Nazário, D., \& Schimtz, G. R. (2015). Terminação de novilhos em pastagem de aveia branca consorciada com leguminosa ou associada à suplementação energética. Arquivo Brasileiro de Medicina Veterinária e Zootecnia, 67(4), 1141-1149. https://doi.org/10.1590/1678-4162-7122.

Knopik, M. A., Rufine, R., Bittencourt, S., \& Gasparotto, F. (2018). Aporte de nutrientes em solos tratados com lodo de esgoto: estudo de caso da região de Campo Mourão, Noroeste do Paraná. Revista Brasileira de Planejamento e Desenvolvimento, 7(3), 379-389.

LAPIG. Laboratório de Processamento de Imagens e Geoprocessamento. Mapa síntese da área de pastagem (MSP) para o território brasileiro. Goiânia: UFG. Lapig: Instituto de Estudos Socio Ambientais, 2018. Disponível em: <https://www.lapig.iesa.ufg.br/lapig/index.php/produtos/atlasdigital-das-pastagens-brasiliras >. Acesso em: Junho de 2020.

Lobo, T. F., Grassi Filho, H., Bull, L. T., \& Kummer, A. C. B. (2013). Efeito do lodo de esgoto e do nitrogênio nos fatores produtivos do girassol. Revista Brasileira de Engenharia Agrícola e Ambiental, 17, 504-509. https://doi.org/10.1590/S0034-737X2012000100017.

Macedo, M. C. M. (2005). Degradação de pastagens: conceitos, alternativas e métodos de recuperação. Informe Agropecuário, 26(226), 36-42.

Maia, F. C. V., Lima, S. O., Benício, L. P. F., Freitas, G. A., \& Furlan, J. C. (2018). Qualidade física do solo após aplicação de lodo de esgoto. Nativa, 6(4), 345-351.

Martins, D. R., Camargo, O. A., \& Bataclia, O. C. (2005). Qualidade do grão e da bebida em cafeeiros tratados com lodo de esgoto. Bragantia, 64(1), 115-126.

Martins, S. S., Pinatti, E., \& Igreja, A. C. M. (2009). Cadeia produtiva da pecuária de Corte: Ciclos pecuários e indicadores de lucro bruto. Congresso Da Sociedade Brasileira de Economia, Administração e Sociologia Rural.

Matos, A. T., \& Matos, M. P. (2017). Disposição de águas residuárias no solo e em sistemas alagados construídos. In Editora UFV (Vol. 1). Universidade Federal de Viçosa.

MCTI. (2014). - Ministério da Ciência, Tecnologia e Inovação (2014). In Estimativas anuais de gases de efeito estufa no Brasil. MCTI.

Mota, M. F. C., Pegoraro, R. F., Santos, S. R., Maia, V. M., Sampaio, R. A., \& Kondo, M. K. (2018). Contamination of soil and pineapple fruits under fertilization with sewage sludge. Revista Brasileira de Engenharia Agrícola e Ambiental, 22, 320-325.

Muir, J. P., Santos, M. V. F., \& Cunha, M. V. (2019). Value of endemic legumes for livestock production on Caatinga rangelands. Revista Brasileira de Ciências Agrárias, 14(2), e5648. https://doi.org/10.5039/AGRARIA.V14I2A5648.

Muller, M. M. L., Guimarães, M. F., Desjardins, T., \& Silva, P. F. M. (2001). Degradação de pastagens na Região Amazônica: propriedades físicas do solo e crescimento de raízes. Pesquisa Agropecuária Brasileira, 36(11), 1409-1418.

Naranjo, J. F., Cuartas, C. A., Murgueitio, E., Chará, J., \& Barahona, R. (2012). Balance de gases de efecto invernadero en sistemas silvopastoriles intensivos con Leucaena leucocephala en Colombia. Livestock Research for Rural Development, 24(150), 15.

Nascimento, A. L., Sampaio, R. A., Cruz, S. F. da, Zuba Junio, G. R., Barbosa, C. F., \& Fernandes, L. A. (2014). Metais pesados em girassol adubado com lodo de esgoto submetido a diferentes processos de estabilização. Revista Brasileira de Engenharia Agrícola e Ambiental, 18, 694-699.

Nascimento, C. W. A., Barros, D. A. S., Melo, E. E. C., \& Oliveira, A. B. (2004). Alterações químicas 
em solos e crescimento de milho e feijoeiro após aplicação de lodo de esgoto. Revista Brasileira de Ciência Do Solo, 28(2), 385-392. https://doi.org/10.1590/s0100-06832004000200017.

Neves, T. I. Aproveitamento energético do biossólido gerado por indústria têxtil como fertilizante para produção de capim-elefante - Cenchrus purpureus (Schumach.) Morrone. Dissestação (Programa de Pós-Graduação em Energias Renováveis

Oliveira, T. C., Pereira, D. N., Brito, T. E., Agostini, J. A. F., Lima, P. F., Silva, A. V., Santos, C. S., \& Bregagnoli, M. (2013). Diagnóstico e recuperação de áreas de pastagens degradadas. Revista Agrogeoambiental, 1(1), 49-53.

Olivo, C. J., Ziech, M. F., Meinerz, G. R., Agnolin, C. A., Tyska, D., \& Both, J. F. (2009). Valor nutritivo de pastagens consorciadas com diferentes espécies de leguminosas. Revista Brasileira de Zootecnia, 38(8), 1543-1552.

Olson, M. E., \& Fahey, J. W. (2011). Moringa oleifera: un árbol multiusos para las zonas tropicales secas. Revista Mexicana de Biodiversidad, 82(4), 1071-1082.

Pedroza, M. M., Vieira, G. E. G., Sousa, J. F., Pickler, A. C., Leal, E. R. M., \& Milhomen, C. C. (2010). Produção e tratamento de lodo de esgoto-uma revisão. Revista Liberato, 11(16), 149-160. https://doi.org/10.31514/rliberato.2010v11n16.p149.

Pegoraro, R. F., Silva, I. R., Novais, R. F., Barros, N. F., Cantarutti, R. B., \& Fonseca, S. (2014). Estoques de carbono e nitrogênio em Argissolo submetido ao monocultivo de Eucalyptus urograndis e em rotação com Acacia mangium. Ciência Florestal, 24(4), 935-946. https://doi.org/10.5902/1980509816607.

Penteado, S. R. (2007). Adubação orgânica: compostos orgânicos e biofertizantes (Vol. 1).

Pereira, M. M., Rezende, C. P., Pedreira, M. S., Pereira, J. M., Macedo, T. M., Silva, H. G. O., Borges, A. M. F., \& Silva, A. M. P. (2015). Valor alimentício do capim marandu, adubado ou consorciado com amendoim forrageiro, e características da carcaça de bovinos de corte submetido à pastejo rotacionado. Revista Brasileira de Saúde e Produção Animal, 16(3), 643-657. https://doi.org/10.1590/s1519-99402015000300015.

Peron, A. J., \& Evangelista, A. R. (2004). Degradação de pastagens em regiões de cerrado. Ciência e Agrotecnologia, 28(3), 655-661.

Pott, C. A., Müller, M. M. L., \& Bertelli, P. B. (2007). Adubação verde como alternativa agroecológica para recuperação da fertilidade do solo Green manuring as an agroecological alternative for the recovery of soil fertility. AMBIÊNCIA, 3(1), 51-63.

Resende Júnior, Joaquim Carlos de. Biossólido na nutrição de Urochloa brizantha cv. Marandu. 2015. 41 f. Dissertação (Mestrado em Agronomia) - Universidade Federal de Uberlândia, Uberlândia, 2015.

Ribaski, J., Montoya, L. J., \& Rodigher, H. R. (2001). Sistemas agroflorestais: aspectos ambientais e socioeconômicos. Informe Agropecuário, 22(212), 61-67.

Ribeiro, R. C., Rossiello, R. P., Macedo, R. O., \& Barbieri Júnior, E. B. (2007). Introdução de desmódio em pastagem estabelecida de Brachiaria humidicola: densidade e freqüência da leguminosa no consórcio. Revista Da Universidade Rural, 27, 41-49.

Rocha, J. H. T., Backes, C., Diogo, F. A., Pascotto, C. B., \& Borelli, K. (2013). Composto de lodo de esgoto como substrato para mudas de eucalipto. Pesquisa Florestal Brasileira, 33(73), 27-35. https://doi.org/10.4336/2013.pfb.33.73.331.

Salgado, V. C., Souza, E. J., Gavazza, S., Florencio, L., \& Kato, M. T. (2018). Cultivo de melancia no semiárido irrigado com diferentes lâminas de esgoto doméstico tratado. Engenharia Sanitária e Ambiental, 23, 727-738.

Santini, J. M. K., Buzetti, S., Galino, F. S., Dupas, E., \& Coaguila, D. N. (2015). Técnicas de manejo para recuperação de pastagens degradadas de capim-braquiária (Brachiaria decumbens Stapf cv. Basilisk). Boletim de Indústria Animal, 72(4), 331-340.

Santos, H. Q., Fonseca, D. M., Cantarutti, R. B., Alvarez V, V. H., \& Nascimento Júnior, D. (2002). Níveis críticos de fósforo no solo e na planta para gramíneas forrageiras tropicais, em diferentes idades. Revista Brasileira de Ciência Do Solo, 26(1), 173-182. https://doi.org/10.1590/s0100-06832002000100018. 
Santos, L. M., Reis, E. M., Silva, F. F., \& Zonetti, P. C. (2011). Tratamento de água residuária de curtume com utilização de sementes de moringa (Moringa oleifera L.). Revista Agro@ Mbiente OnLine, 4(2), 96-101.

Santos, P. M., Santos, A. C., Neiva, J. N. M., \& Neves Neto, D. N. (2016). Desempenho de ovinos em sistema agroflorestal alternativo no ecótono Cerrado: Amazônia. Revista Brasileira de Saúde e Produção Animal, 17(4), 584-598. https://doi.org/http://dx.doi.org/10.1590/S1519-99402016000400003

Silva, A., Simioni, G., \& Lucena, A. (2013). Efeito da adubação orgânica no crescimento do capim Brachiaria brizantha cv. marandu em Parecis/Rondônia. Enciclopédia Biosfera, 9(16).

Silva, C. F., Loss, A., Carmo, É. R., Pereira, M. G., Silva, E. M. R., \& Martins, M. A. (2015a). Fertilidade do solo e substâncias húmicas em área de cava de extração de argila revegetada com eucalipto e leguminosas no Norte Fluminense. Ciência Florestal, 25, 547-561.

Silva, L. L. G. G., Resende, A. S., Dias, P. F., Correia, M. E. F., \& Scoriza, R. N. (2015b). Soil macrofauna in wooded pasture with legume trees. Ciência Rural, 45, 1191-1197. https://doi.org/10.1590/0103-8478cr20131569.

Siqueira, D. P., Barroso, D. G., Carvalho, G. C. M. W., Erthal, R. M., Rodrigues, M. C. C., \& Marciano, C. R. (2019). Lodo de esgoto tratado na composição de substrato para produção de mudas de Plathymenia reticulata Benth. Ciência Florestal, 29(2), 728-739. https://doi.org/10.5902/1980509827297.

SNIS - Sistema Nacional de Informação sobre Saneamento. Painel de esgoto sanitário. Brasília, 2018. Disponível em: http://www.snis.gov.br/painel-informacoes-saneamento-brasil/web/painelesgotamento-sanitario. Acesso em: Maio de 2020

Van Haandel, A. C., \& Lettinga, G. F. (1994). Tratamento anaeróbio de esgotos: um manual para regiões de clima quente. Epgraf.

Varella, A. C., Porfírio-da-Silva, V., Ribaski, J., Soares, A. B., Moraes, A., Morais, H., Saibro, J. C., \& Barro, R. S. (2009). Estabelecimento de plantas forrageiras em sistemas de integração floresta-pecuária no Sul do Brasil. In R. S. Fontaneli, H. P. Santos, \& R. S. Fontaneli (Eds.), Forrageiras para integração lavourapecuária-floresta na região sul-brasileira (Vol. 1, pp. 283-328). EMBRAPA.

Yada, M. M., Melo, W. J. de, Mingotte, F. L. C., Melo, V. P., \& Melo, G. M. P. (2015). Chemical and biochemical properties of oxisols after sewage sludge application for 16 years. Revista Brasileira de Ciência Do Solo, 39, 1303-1310.

Zen, S., Barioni, L. G., Bonato, D. B. B., Almeida, M. H. S. P., \& Ritti, T. F. (2008). Pecuária de corte brasileira: impactos ambientais e emissões de gases efeito estufa (GEE). Esalq/Cepea.

Zuba, G. R., Sampaio, R. A., Nascimento, A. L., Fernandes, L. A., Lima, N. N., \& Carneiro, J. P. (2015). Attributes of the soil fertilized with sewage sludge and calcium and magnesium silicate. Revista Brasileira de Engenharia Agrícola e Ambiental, 19, 1107-1113.

Histórico do artigo:

Recebido: 16 de outubro de 2021

Aprovado: 19 de novembro de 2021

Disponível online: 21 de fevereiro de 2022
Licenciamento: Este artigo é publicado na modalidade Acesso Aberto sob a licença Creative Commons Atribuição 4.0 (CC-BY 4.0), a qual permite uso irrestrito, distribuição, reprodução em qualquer meio, desde que o autor e a fonte sejam devidamente creditados. 